\title{
An Aboriginal Adult Literacy Campaign Pilot Study in Australia using Yes I Can
}

\author{
BOB BOUGHTON, DONNA AH CHEE, JACK BEETSON, \\ DEBORAH DURNAN and JOSE 'CHALA' LEBLANCH
}

\begin{abstract}
In 2012, the remote Aboriginal community of Wilcannia in western NSW hosted the first Australian pilot of a Cuban mass adult literacy campaign model known as Tes I Can. The aim was to investigate the appropriateness of this model in Aboriginal Australia. Building on an intensive community development process of 'socialisation and mobilisation', sixteen community members with very low literacy graduated from the basic literacy course, with the majority continuing on into post-literacy activities, further training and/or employment. The pilot was initiated by the National Aboriginal Adult Literacy Campaign Steering Committee (NAALCSG) consisting of Aboriginal leaders from the education and health sectors, and managed by the University of New England (UNE), working in partnership with the Wilcannia Local Aboriginal Land Council as the local lead agency. The pilot was supported by a Cuban academic who came to Australia for this purpose, and included a Participatory Action Research (PAR) evaluation led by the UNE Project Manager. In this paper, members of the project team and the NAALCSC describe the pilot and reflect on its outcomes.
\end{abstract}

\section{Introduction}

In 2012, the remote Aboriginal community of Wilcannia in western New South Wales hosted the first Australian pilot of a Cuban mass adult literacy campaign model known as Yes I Can, or more commonly in the international literature, by its Spanish title, Yo Si Puedo (UNESCO 2006). The pilot was initiated and overseen by the National Aboriginal Adult Literacy Campaign Steering Committee (NAALCSC), consisting of Aboriginal leaders from the education and health sectors, and managed by the University of New England (UNE), working in partnership with the Wilcannia Local Aboriginal Land Council as the local lead agency. Several members of the project team had previous experience of the Yes I Can model in other countries, including most recently in Timor-Leste, where it was used for that country's national literacy campaign (Boughton 2010, 2012). This study used participatory action research to examine the feasibility of upscaling this same model to undertake a mass literacy campaign in 
Aboriginal Australia. Core funding was provided by the WELL (Workplace English Language and Literacy) Strategic Projects Program of the Commonwealth Department of Innovation, Industry, Science and Research supplemented with grants and in-kind support from other Commonwealth and State agencies and a major corporate sponsor, Brookfield Multiplex. ${ }^{i}$

While mass literacy campaigns are the subject of an extensive research literature in the field of international and comparative education (e.g. Abendroth 2009, Arnove and Graff 2008, Bhola 1984, 1999, Freire 1978, Miller 1985), they are not a feature of the Australian literacy landscape. So, before describing the Wilcannia pilot in detail, we begin with some historical background, and a description of the three phase campaign model. This is followed by an account of the pilot's design and research methodology. Next, we review some of the experiences during the pilot, and the main outcomes achieved. We end with our findings and conclusions from the pilot study. As the NAALCSG has decided to continue with a further pilot, this paper should be read as a work-in-progress rather than a definitive study of the model and its applicability in Australia.

\section{Background}

The Aboriginal leaders and adult educators involved in this project have been working together over many years to address the low levels of literacy in English in the Aboriginal adult population, which we consider to be an important contributing factor to poor health outcomes and a major barrier to people's capacity to take greater control of their lives and communities. In the 1990s, supported by the Co-operative Research Centre for Aboriginal Health (CRCAH), we studied the experience of countries of the Global South which had achieved low rates of infant mortality and better health outcomes through the so-called 'low road to health' (Gray and Smith 1995). In many of these countries, mass adult literacy campaigns had played a significant role in health development (Boughton 2000, Caldwell 1986, Sandiford, Cassel, Montenegro and Sanchez 1995). These findings, which resonated with our research on community-controlled adult education (Ah Chee, Beetson and Boughton 1997, Beetson 1997, Durnan and Boughton 1999), led us to recommend trialling a popular education literacy campaign in Australia (Bell, Boughton and Bartlett 2007). This was in no way an endorsement of a simplistic cause-effect model of literacy and development, which has been thoroughly critiqued by Street (2001), Robinson-Pant (2000) and Rogers (2011). Rather, our proposal was rooted in the dialectical concept of the relationship between learning and social change articulated by authors such as Paulo Freire (Freire 1972, Freire and Macedo 1987) and Paula Allman (2010). 
In 2006, the Government of Timor-Leste invited Boughton, Beetson and Durnan to conduct an in-country evaluation of their national adult literacy campaign which began that year using the Cuban Yes I Can model (Boughton 2010). In 2009, we reported our experiences to a workshop convened by the CRCAH (since renamed the Lowitja Aboriginal Health Research Institute) and the NAALCSC was formed (Boughton 2009). With seed-funding from the Lowitja Institute, the NAALCSC spent two more years investigating the model and lobbying for funds before receiving an invitation from the Commonwealth to apply for funds to conduct this pilot study.

The NAALCSC chose Wilcannia as the first pilot site, where Beetson, an NAALSC founding member, was working as the acting CEO of the Local Aboriginal Land Council (the 'LALG'). Located in western New South Wales on the banks of the Darling River, the town is home to the Baakintji people ('of the river'). The region has been occupied by Aboriginal people for millennia, and includes one of the world's oldest burial sites. British invasion began in the 1830s as the pastoral frontier moved west, initiating a period of "sustained violence" against the local occupants (Goodall 2001, p.20). Proclaimed in 1866, by the 1880s the town had become a thriving river port, with a population of several thousand, and two hundred riverboat steamers stopping there to take on "the majority of the wool from North Western NSW" (Gibson 2006, p.14). Aboriginal people were the backbone of the pastoral workforce, but few lived in the town until after World War 2, and most were then confined to 'shanty town' camps along the river's eastern bank (Beckett 2005). In the 1970s, a national civil rights and land rights movement saw the rise of local Aboriginal organisations, and Baakintji leaders played a significant role in the movement across NSW. Government housing was eventually built in two areas, an old 'Mission' block on the eastern side of the river, and 'The Mallee', on the town's north western edge. Title to this land and the houses was transferred to the LALC in the 1980s. The 1970s struggles, however, could not avert a steady economic decline, resulting from drought, falling pastoral industry profitability, and reduced mining activity in nearby Broken Hill. Today, there is a small hospital, but no resident doctor. The schools, the hospital and the local government are the town's only significant employers, and most families are reduced to a state of semi-permanent dependency on government income support. This decline has seen a rise in symptoms of personal and social disempowerment, including chronic illness, substance abuse, and community and domestic violence. At the 2011 census, the population was 602, of whom 467 (78 percent) identified as Aboriginal (Australian Bureau of Statistics 2011). The Aboriginal population aged 15 
and over, not in school or post-school education, was 280. Of this number, 170 (60 percent) had left school at Year 9 or earlier.

The LALG is the town's only elected local Aboriginal body, with responsibility under the NSW Land Rights Act to represent the community on matters of economic and social development. Beetson secured additional support for the campaign from the local NSW Department of Education Central School, and the Wilcannia Aboriginal Community Working Party (WACWP). Project management and evaluation was undertaken by the University of New England (UNE), whose contract with the Commonwealth specified that:

The aim of the project is to trial a twelve-month pilot campaign. This must utilise an internationally-recognised mass campaign model, not previously deployed in Australia. You must assess whether this model can be applied successfully in an Aboriginal community; and to discover what would be involved in up-scaling it from community to regional level, and then to other regions.

\section{Mass literacy campaigns}

Throughout the world, over 800 million adults are illiterate, of whom the majority are women, and international development agencies and scholarly opinion regularly identify this as a major obstacle to efforts to overcome poverty and marginalisation (Archer 2005). While literacy scholars associated with the New Literacy Studies (e.g. Street 2001, 2011) rightly question the simple equation of literacy with development, the extension of literacy continues to be a major goal of international agencies and national governments (Wagner 2011). For much of the last half of the twentieth century, international bodies such as UNESCO and the International Council of Adult Education (ICAE) believed that literacy campaigns provided an effective means to overcome low literacy in countries of the Global South. In a UNESCO-sponsored study reflecting this view, Bhola defined a literacy campaign as:

A mass approach that seeks to make all adult men and women in a nation literate within a particular time frame. Literacy is seen as a means to a comprehensive set of ends - economic, social, structural and political...(It) suggests urgency and combativeness... it is something of a crusade (Bhola 1984, pp 35 and196, authors' emphasis) 
Support for this approach was fuelled by the successes of mass campaigns in several newly-independent countries, of which the best known examples included Cuba in 1961, Tanzania 1971-1983, Mozambique 197879 , and Nicaragua in 1980. In fact, as a recently re-released collection of country studies reveals, literacy campaigns have a much longer history, going back several centuries, and have occurred under many different types of regimes and in very different historical and political contexts (Arnove and Graff 2008). Many are continuing, including India's Total Literacy Campaign which began in the state of Kerala in 1988 and is still running (Saldanha 2010). Moreover, their impact has been considerable. Literacy rates, defined quite narrowly in terms of people's ability to read and write a few simple sentences, have risen by more than twenty percentage points in several countries, while many participants, both 'graduates' and teachers, have subsequently played a significant role in their country's development (Bhola 1984, Lind 2008).

Our initial review of the literature (Boughton 2009) revealed that, while each campaign included characteristics specific to its country context, most had three key elements, or phases. Phase One, which we call 'socialisation and mobilisation', mobilises as many people as possible to take part, as learners, teachers, organisers and supporters, and seeks to enhance the understanding of society as a whole of the importance of literacy to wider social and economic development goals. It also builds organisation at national, regional and local levels to lead the campaign, widening the responsibility for raising literacy levels beyond the government education authority, enlisting support and commitment from all government agencies, from non-government and civil society organisations and from the community as a whole. This process continues throughout the campaign. The term socialisation is particularly pertinent, since it alerts us to the fact that the campaign model sets out to identify low levels of literacy as a social, not an individual problem. The second element, Phase Two, consists of a set of basic literacy lessons, run over a short period, usually three months or less, in which non-literate and low literate members of the community are encouraged to enrol and supported to complete. These lessons are usually non-formal, rarely accredited, and taught and organized by nonprofessional local facilitators and leaders in the community, with the assistance of professional advisers and materials provided by the central campaign authority. The classes often end with a local ceremony, honouring the people who have completed and welcoming the next group into the classes. The final element, Phase Three of the campaign, is for 'post-literacy'. This consists of activities designed to help the newly-literate participants continue to build their literacy beyond what has been achieved in the basic lessons, and to create a more literate culture in the community. In some 
countries, this post-literacy phase has led into more structured courses taking people up to a basic education level, or into vocational qualifications.

Throughout the process, the central authority maintains a close oversight of progress, with a view to ensuring that targets for literacy improvement are met at a sufficiently rapid rate. All three phases continue until virtually everyone in the community or regions has achieved a basic level of literacy, in accordance with the UNESCO definition used for the literacy targets in the Education for All policy, i.e. 'the capacity of young people and adults aged fifteen and over to read and write, with understanding, a simple sentence about their own life' (UNESCO 2005:.29).

Literacy campaigns thus provide a very different approach to the problem of low literacy levels from the literacy programs we are accustomed to seeing in Australia and, indeed, in most western countries. Literacy programs are small-scale, discrete, usually-accredited courses of semi-formal study, run through adult learning centres and vocational colleges, or in the workplace, with students who self-select and professional adult literacy teachers who are usually from outside the community. Their main focus is on individuals acquiring skills. These programs are usually the responsibility of Education Departments, though there is also a lot of NGO activity. The approaches are hugely varied, as are the success rates of the students in the different programs. The large-scale mass campaign is quite different. It involves a nationally, or at least regionally-coordinated attack on the problem of illiteracy, usually led by government but involving all sectors of society. It aims to reduce adult illiteracy by a specific amount over a specific period, and thereby help to transform the whole community.

International interest in mass campaigns declined in the 1990s, in part because research commissioned by the World Bank claimed that their success rate was only 12 percent (Abdazi 1994), a view since shown to be incorrect (Lind 2008, p.46). There can be little doubt that part of the opposition to wider international sponsorship came from the West, which was concerned about the association of many successful campaigns with socialist regimes and anti-colonial independence movements (Jones 1990). Nevertheless, many countries in the Global South continued to mount successful campaigns, the most recent examples including Argentina, Bolivia, India, Venezuela, Grenada and Timor-Leste. In the last ten years, interest in the mass campaign model has re-surfaced, stimulated in part by the United Nations Literacy Decade, which ended in 2012 (UNESCO 2005).

Contemporary literacy scholars, especially those working in universities of the North, remain divided about the value of mass campaigns. It is not possible in the space of this article to review all the arguments, but criticism has been directed at the unreliability of the statistics that measure the apparent gains; the subsequent 'falling -off' of literacy levels when 
campaigns are not followed up and supported with comprehensive systems of school and post-school education; the tendency of campaigns to promote a 'one-size-fits-all' 'autonomous' model of literacy, which devalues local knowledge and local literacy practices; the poor quality of the actual instruction, related to the use of volunteer and untrained tutors and facilitators; and the overly-political intent of some campaigns (Abdazi 1994, Wagner 2001, Street 2001, Latin American Group of Specialists in Literacy and Written Culture [GLEACE] 2009). On the other hand, mass campaigns still receive considerable support around the world, from governments, especially those with a social reform agenda; from literacy advocates and practitioners working through governments and international agencies (Bhola 1999, Lind 2008); from scholars and practitioners working in the tradition of popular education (e.g. Abendroth 2009, González 2005); and, not least, from the millions of people who choose to participate in them. Ultimately, the test of their value will be whether or not they have a positive impact upon the populations, societies and communities involved, something which only empirical research on actual campaigns can reveal.

\section{The pilot and the research}

In the 1990s, the Federation of Independent Aboriginal Education Providers (FIAEP), a national body representing Aboriginal communitycontrolled adult education colleges, developed a participatory action research (PAR) model to help overcome some of the inherent difficulties of doing research in their communities (FIAEP 1997). PAR, a commonly-used approach to the evaluation of education and development interventions in the Global South (Kapoor and Jordan 2009), has been defined as:

a form of collective self-reflective inquiry undertaken by participants in social situations in order to improve the rationality and justice of their own social or educational practices, as well as their understanding of these practices and the situations in which these practices are carried out (Kemmis and McTaggart 1988:,5, authors' emphasis).

The participants in this study included the UNE Chief Investigator, members of the NAALCSC, the on-site project team, local community members and representatives of local agencies, and staff from the funding bodies. The research design was approved by UNE's Human Research Ethics Committee.

This was a pilot, rather than a trial. The assumption was made at the outset that the campaign would need to deliver benefits to the community, but that how to do this, how to run an actual campaign in such a context, could not be known in advance. The campaign model chosen for the pilot 
was the one we had observed and evaluated in Timor-Leste, developed by the Institute of Pedagogy for Latin America and the Caribbean (IPLAC) in Havana, Cuba. The model has been deployed in twenty eight countries since it was first developed in 2000, and has been the subject of an evaluation study by UNESCO and the recipient of a major UNESCO Literacy Prize. In UNESCO's words:

[T] he $\operatorname{YSP}\left[Y_{0}\right.$, si Puedo $]$ method is in fact more than a method. It would be more appropriate to understand it as a literacy training model that goes beyond processes, materials, strategies etc., as it includes, both explicitly and implicitly, concepts of literacy training, learning, life skills and social mobilization, and involves a wide range of actors with varied roles from the beneficiaries of the literacy training to other stakeholders such as state entities and other concerned institutions. (UNESCO 2006)

YSP follows the general form of the three phases described above, with a specially-designed method of teaching during Phase Two, using preprepared DVDs and workbooks.

A pilot in one community is not in itself a campaign. Rather, this was an exploratory exercise, undertaken to decide whether a campaign itself is feasible. A pilot can put in place various aspects of the model, including the three phase approach; it can identify some of the strengths and weaknesses of the model and the method; it can reveal aspects of a specific national or regional context which a mass campaign will need to address; and it can therefore help in deciding how, if at all, a large scale campaign could be mounted. However, without the critical mass and momentum which the campaign proper generates, a pilot cannot be expected to have as significant an impact. That said, the pilot was designed to provide as much information as possible on which future decision-making could be based. Data were collected from a variety of sources, including previous research on the community, and the 2011 Australian Bureau of Statistics Census data; an initial household literacy survey; a purpose-built database of enrolment, participation and outcome data; student files, including examples of work; pre- and post- testing of participants; in-depth interviews with a selection of participants, facilitators and community stakeholders; participantobservation of campaign activities; written reports from project team members; and other primary source data including media reports, photographs and film of campaign activities, and minutes of meetings and workshops with the Project Team, the Steering Committee and the funding agencies. Regular reports from the evaluation research were discussed in 
project team meetings and with the NAALSC, to seek further response and commentary from project participants.

\section{The experience of the campaign}

\section{Phase One: socialisation and mobilisation}

On Tuesday 7th February, 2012, over 200 locals and visitors gathered in Baker Park, on the banks of the Darling River, for the public launch of the campaign, in what the Wilcannia News, quoting a local elder, described as 'one of the best days in Wilcannia for many years.' The MC, local Aboriginal health worker Belinda King, introduced the crowd to various speakers, including Jack Beetson, Chris Hunter representing the local campaign facilitators, Jose 'Chala' Leblanch, the Cuban adviser who had arrived in town only two weeks earlier, and a visitor from Timor-Leste, Zelia Fernandes, who had worked on her country's literacy campaign. Save the Children ${ }^{\mathrm{ii}}$ organised activities for the younger children, the students from both schools came, the Baakintji dancers performed, a local businessman provided the mobile gas BBQ on which he and two other volunteers cooked emu rissoles and kangaroo kebabs, and a band played country music. The NSW regional Aboriginal Land Councillor, Des Williams, was there, and the Central Darling Shire President, along with a representative of one of the campaign sponsors, Brookfield Multiplex, members of the NAALC, and a delegation from the Central Australian Aboriginal Congress in Alice Springs.

This event, the culmination of the initial Phase One work, illustrates a key feature of the model, which requires literacy to be seen as the responsibility of the whole community, rather than a problem for individuals. This idea becomes a material reality through establishing and/or engaging local structures to lead the campaign. Initially, a small working group was assembled, chaired by the leader of the local Aboriginal Education Consultative Group (AEGG). A team of employees and volunteers from other organisations then began working together to get the campaign off the ground, supported by Beetson and his technical adviser on the project, Deborah Durnan. Over time, the Land Council increasingly became a hub of activity. Campaign workers and volunteers also became engaged in other Land Council and Community Working Party activities which centred on the Land Council offices, adding to the sense of community mobilisation, and reinforcing the point that literacy cannot be addressed in isolation from the wider social issues of which it is a part. In December and January, a simple household survey to identify the level of need and interest was undertaken by local community members, eventually reaching 41 households with 119 adult residents. 
Of these, 98 were identified by themselves or a family member as needing assistance with literacy, and 45 registered to join a class.

Our Cuban adviser arrived in Australia in mid-January 2012, and almost immediately travelled to Wilcannia to begin work. By the end of the week he had met the Working Group, been oriented briefly to the town and the community, and held an initial orientation session for potential facilitators. The following Monday, the two weeks of facilitator training began in earnest, with four volunteers, along with the local radio station DJ, who came along to train as a back-up person, and the post-literacy coordinator. The first classes began in mid- February, with a total of 26 people enrolled.

These 26 people came from a cohort within the community with little prior education, a history of disengagement from employment and community development, and many pressing and difficult issues in their lives. For these people, enrolling in such an activity was a major step. The students would not have enrolled if there had not been a strong feeling of community support around them, and if the local facilitators had not encouraged them to do so. Nor would the community have been as supportive, if they had not seen that the campaign was something they could play a role in and help direct. However, it is also important to recognise that underlying the support for the campaign, both from the wider community, from the facilitators and staff, and from those who enrolled, was a clear recognition of need. As one of the facilitators recalled:

Well when it first come to Wilcannia, when we got the first lot of students, one of the good things about it was the talk around town. Everyone was happy about it. The whole community was talking about this Yes I Can program. The students that got involved they go back and tell other students and mates or friends. I'm just happy to hear them all talking about it, when you're sitting around the campfire, making the 'Fohnny Cake' and kangaroo stew you know. I was just happy to hear someone talking about it (Owen Whyman Interview, 26/7/2012).

The work of Phase One was made difficult by a number of community crises, including several deaths in the last three months of 2011, and a serious civil disturbance. In a small community, which already has a history of conflict with various authorities and agencies and disputes between families, such events reverberate for an extended period, and make it difficult for some people to come to work, or to take part in meetings together. Funerals and court cases also take people away from other things, and sometimes from the town itself. In short, one of the consequences of a high degree of community engagement and ownership of the campaign is 
that it becomes subject to the same ups and downs as the community itself. Moreover, the closer the campaign is to the people who most need it, the more the chaos of life at the margins intrudes on the campaign's own organisation.

'Socialisation' is not a word with which English-speaking practitioners and scholars will necessarily be familiar, but it carries an important meaning. We are accustomed to think of literacy in individual terms, even though theory and research, especially in recent decades, has emphasised its social nature. As Luke and Freebody (1999: 4) write:

while literacy is an aspect of an individual's history, capability, and possibilities, it is also a feature of the collective or joint capabilities of a group, community, or society.

The socialisation work in a campaign, which does not stop when classes start but continues throughout the campaign, is a practical expression of this theoretical point, because it makes the task of improving literacy a task for the community. In other words, the socialisation is not something done before the 'real' work of tuition in the literacy classes. Rather, it is an essential ingredient of the work of building community literacy.

\section{Phase Two. The Yes I Can classes}

In Phase Two, two intakes of students, 43 in all, undertook the basic literacy lessons, taught using Yes I Can resources and method described below. Each intake ran for 12 weeks, the first from February until May, and the second from May until August, with a break for the school holidays. In the first intake, there were two classes, one in the morning and one in the afternoon, while there was only one group in the second intake.

Chala brought with him from Cuba a boxed set of DVDs, on which were recorded 64 lessons which IPLAC had made for the literacy campaign in Grenada in 2007. The other resources were printed work books for each student, containing the exercises to be done during the lessons, and copies of a simple facilitator's handbook, explaining the method and the facilitator's role. Each Yes I Can class followed a similar format. Students would arrive, having been picked up by a campaign worker or having walked to class from home. They would socialise a little, and then sit down to watch a DVD lesson, each of which ran for approximately twenty five minutes. During this time, the facilitator can turn it on and off, to allow the students to complete activities, including discussing what they have seen and asking questions. On 
the TV, they watched a literacy class, taught to a group of five people by a lead teacher and an assistant. All the people in the TV class are actors, working to a script. The teacher takes her class through each lesson, using an alphanumeric method in which they first learn to associate letters with numbers, following a 'Guide Table', and then undertake exercises to build words, phrases and, eventually, sentences and texts of different genres.

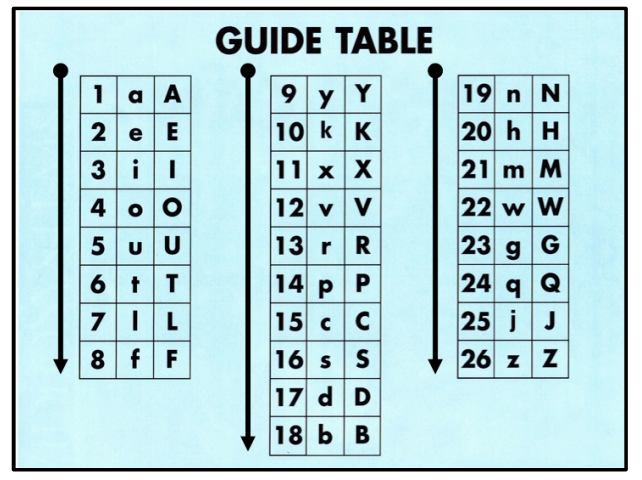

\section{Figure 1. The Yes I Can Guide Table}

Each lesson begins with a 'positive message', a type of generative theme, a phrase in which there are words containing the letter or letters which are the focus of that lesson, but which makes a specific point or raises an idea. The first phrase is simply 'Open the gate', the message being that literacy is opening up a new world and you are on a new journey. On the DVD, discussion around these themes with the actor-students is led by an assistant teacher, with the help of film clips illustrating aspects of Grenadian life. Later themes include looking after the environment, caring for children, nutrition and the role of women. The student-actors are of varying ages, men and women, and with different levels of confidence and expertise. The lessons all follow a predictable pattern, or 'algorithm', and the students in Wilcannia quickly learned the sequence. There are also icons used throughout each lesson to identify specific activities of observing, listening, speaking, reading and writing. Each lesson includes a brief general knowledge element, related to the initial 'positive message.'

The lessons are divided into three stages. There are seven basic introductory lessons, 45 reading, writing and revision lessons, and 12 consolidation and extension lessons with assessment activities. Lesson 65 is an evaluation activity for the facilitators. Lessons $2-7$ are designed for people with no prior experience of reading and writing, and include exercises to practise holding a pen and forming simple shapes. Since every student in Wilcannia had at least some minimal primary schooling, the 
facilitators elected, following the first lesson which introduces the method, to skip the next six, going straight to Lesson 8, which begins the work on letters of the alphabet, basic words and phrases. After some experimentation, it was decided to show a minimum of five lessons per week, in three sessions of two hours each, on Mondays, Tuesdays and Wednesdays. A 'catch-up' session was held on Thursdays, for people who had missed lessons or wanted to repeat them. On Fridays, though not every week, there was a 'Literacy and Culture session', sometimes followed by a BBQ. This was introduced at the facilitator's suggestion, and was an opportunity for the students and facilitators to tell Chala about their country's history, culture and issues; and for him to talk about Cuba and the Caribbean.

The most important part of the model is that the lessons are 'taught' by the local facilitator, who sets up the class, controls the DVD, leads the discussion of the 'positive messages' and sets and supervises the learning activities:

It's not just locals learning from locals, but family learning from family, so they understood each other, they had an empathy with each other... that you just don't get otherwise. If you bring teachers in from Cobar or Broken Hill or anywhere else, they don't belong in the community, they're not from the community (whereas) these people knew what they'd all gone through, they understood that and I think that was the key factor in it working. (Jack Beetson, ABC radio interview, $10 / 5 / 12)$

While there were often one or two technical advisers present, their role was to provide ongoing monitoring, training and critical reflection. At times, they might move to the front of the class to demonstrate or explain; but in general they stayed back, and worked as assistants to the local facilitators outside the class. The advisers' role was to help the facilitators prepare each lesson, to discuss what had happened in a previous class and progress of each student, and to assist with ideas on how to contextualise and adapt the materials to the reality of Wilcannia. This contextualisation, a key feature of the Yes I Can model, involves finding local pictures, words and themes to use in lessons, as a substitute for unfamiliar words used on the DVD, or in addition; and preparing additional localised resources to match students' needs.

Completion of the basic 64 lessons indicates a minimal level of achievement on some simple tasks, even though the method does allow people to achieve more than this if they are able. The minimum requirement is that they are able to write independently a short letter about 
their own life. The final evaluation of the students' learning occurs during the activities in lessons 56 to 63 and each participant's work is recorded in his/her workbook and exercise book. There is no formal assessment test, but the advisers have to verify with the facilitators that everyone who completes has reached this basic level.

However, the course as a whole is designed to achieve much more than this. The 'positive messages' express an underlying set of values about human development and the role of each individual within it. The Cuban Ambassador to Australia, who was a brigadista himself in the 1961 Cuban literacy campaign, described it thus at the May graduation

...the system is very well conceived, since the process starts with the discussion of ideas (before) establishing links between numbers and words. In fact, the program is not limited to teaching reading and writing. It integrates educational, social and cultural components with the learning process of reading and writing, and the framework of the teaching is referred to the cultural and social interest of the local people (Monzon, P, personal communication).

There is also a significant amount of material which could be called general knowledge, which introduces students to the world of learning and the possibilities of a better future.

\section{Participation and retention}

In the first intake, while 25 people actually came to one or more classes, 12 withdrew after only one or two sessions, leaving 13 continuing students. Of these, 10 graduated, which is a retention figure of over 75 percent, an unusually high figure for Aboriginal post-school education courses. The second intake had a lower retention (55 percent), with 11 continuing students and 6 graduating. The participation and retention across both intakes are set out in Table 1, below. This shows that, of the students who attended two or more times, only eight did not successful complete the classes.

Table 1. Participation and retention, Intakes 1 and 2, Wilcannia 2012 


\begin{tabular}{|l|c|c|c|}
\hline \multicolumn{4}{|c|}{ Participation and retention } \\
\hline & M & F & T \\
\hline Starters & 14 & 29 & 43 \\
\hline Continuers & 8 & 16 & 24 \\
\hline Completers & 5 & 11 & 16 \\
\hline Retention & $62.5 \%$ & $68.8 \%$ & $66.7 \%$ \\
\hline Withdrawals & 6 & 13 & 19 \\
\hline W \% starters & $42.9 \%$ & $44.8 \%$ & $44.2 \%$ \\
\hline
\end{tabular}

The reasons for withdrawal were often to do with significant personal crises, including one student being jailed half way through the classes, and two more having to leave town to go and look after a critically-ill relation in another town. Another withdrawal was a young man whose mother had withdrawn him from school, who returned to school after six weeks, which was an excellent result. Some 'withdrawers', it should be noted, have actually come back into the campaign to take part in the post-literacy phase, suggesting that they are still building their literacy levels. The retention rate across both intakes for both men and women show that, for the people who were mobilised to join the campaign, and who stayed beyond the first one or two sessions, the model and method is effective in helping them achieve a basic level of improved literacy.

\section{Independent testing of outcomes}

Because the assessment process is built into the Yes I Can lessons, completion data is the indicator of the outcomes achieved, since all who complete have achieved the very basic level which is the minimum standard described earlier. However, for the pilot, the NAALCSC agreed to the Commonwealth's request for additional data, through mapping the Yes I Can lesson content against the Australian Core Skills Framework (ACSF) and using that national standard to assess the literacy levels of participants at the beginning and end of Phase Two. This work was carried out by an independent consultant, Philippa McLean, one of the original architects of the ACSF. On her advice, the mapping and assessments were confined to three of the five 'core skills', learning, reading, and writing. Mclean determined that Yes I Can allowed students to develop across a fairly broad range, from below Level One on the ACSF when lessons began to Level Two and perhaps even higher, at the end: 
The early stages of the Yes I Can course concentrate on single sounds for reading, writing and oral communication. As the learner develops through the course the emphasis is on building knowledge of words (ACSF Pre Level 1), then sentences working from simple to complex sentences (ACSF level 1 to level 2). Learners then spend time developing skills to write a paragraph and a descriptive informal letter to a friend using a model provided (ACSF level 2). It isn't until near completion of Yes, I Can that learners are creating paragraphs with support....

......(BUT) the pace, modelling and restricted context of the classes and step by step process means that Tes I Can rarely operates above ACSF level 1 (Mclean 2012)

However, as her report acknowledges, there is a lot more happening, some of which falls outside the ACSF, but is nevertheless contributing to the participants' literacy development:

A number of participants commented on how they enjoyed learning about Cuba and Granada. They showed obvious interest in having their horizons extended ...

The methodology of Yes, I Can is such that the priority is for learners to achieve success and build confidence. Risk taking is not as strong a focus, so there is significant support and scaffolding for all activities. This means that the program is rarely able to provide the participants with the opportunity to demonstrate higher than ACSF level 2 performance and often performance opportunity is only at level 1 . (Authors' emphasis added)

In the pre-assessments, the majority of students were in fact at PreLevel One (PL1), i.e. not actually on the original ACSF scale. The final assessments showed a dramatic change for those who had persevered with improvements in one or more core skills.

Overall, the consultant's conclusion was that Yes I Can had provided an opportunity for significant literacy building:

This was demonstrated in ways such as attempting to write more complex sentences without support, speaking up in class and coming to the whiteboard to write, reading aloud to the class from the DVD, supporting class members, working in groups and connecting their classroom work with their broader life. 
In relation to the development of core skills more generally, one of the consultant's most significant findings was that:

The core skill of 'Learning' is a critical skill that needs to be explicitly addressed by teachers and learners. Development in this skill often underpins progress in the other core skills

(McLean 2012).

From the qualitative data, it is clear that a whole set of other factors underpin the development of the 'skill' of learning, of which the most important is the belief which individuals and the group as a whole develop through the course, a belief in their own ability to learn and to improve the situation in which they find themselves and their families. Many people saw the literacy campaign as a chance to turn their lives around, build their confidence, and play a more positive role in their community. One participant put it this way:

I heard from friends and I wanted to get involved, to build my confidence up again, because I was into drugs and alcohol. And I came along, got involved with it and I just enjoyed it. (On the first day) I felt shy. I was so shy, I hardly spoke. I knew the people in the class but I hardly spoke to 'em. I was shy in the class and even out on the street. (Participant interview, 27/6/12).

The diversity of motivations is reflected in the following extract from the Senior Technical Adviser's Report. The phrases in quote marks are the participants' words:

Some of the older women simply wanted to have a better quality of life for both themselves and their kids and grandkids. It was not unusual for the women to comment that 'they loved coming to class because it was boring at home all day everyday with nothing different to do.' One older person said she hopes the young ones see her and want to do it also, to 'make something of themselves. Not sitting all day at home watching videos'. One younger women said 'class made me feel better inside' because it helped her deal with her sadness of losing her two young children in an accident only two years before. Two women specifically came to $R E S I C A \mathcal{N}$ so they could 'stay clean', 'off the grog and drugs'. A young man with a newly- 
born daughter and young son spoke of becoming 'a role model for family maybe work at Shire'; an older man had decided YES I CAN would help him 'get fit and play footy again so he can stay strong and off grog and get work'. Another grandmother wanted 'the rest of my family to do course, show them if I can do it they can too'; a woman said she really wanted to 'look out for grand kids'; a younger woman said she 'just wanted to feel happier'; and another 'my kids be proud of me, they shamed when I don't read'. Two women were desperately trying to turn their life around in order to stay out of gaol as they had run out of chances being on a suspended sentence (Durnan 2012).

\section{The graduations}

The culmination of Phase Two for both intakes came with the graduations, which took place on May $9^{\text {th }}$ and August $31^{\text {st }}$. These significant community events were a continuation of Phase One, because they contributed to the socialisation and mobilisation, building more understanding within the community of the importance of literacy and the need to honour and support the people in the community who join the classes. In recognition not only of the graduates, but of the community as a whole for their efforts in mounting the campaign, the second and final graduation was attended by the Commonwealth Parliamentary Secretary, Ms Sharon Bird, responsible for the Foundation Skills area, and by John Williams, the local National Party Member for the region in the NSW Parliament. The Cuban Ambassador, His Excellency Pedro Monzon, attended both graduations, possibly the first time such a high-level international guest had visited the community. Both graduations received extensive positive coverage in local, regional and national media, adding to the pride felt by the participants, their families and friends, and the campaign's many supporters. Jack Beetson captured this in his speech to the August graduation:

I am proud of this campaign for many reasons but one reason is because over 40 adults were courageous enough to step through the classroom door to take a look; ... today we are honouring the 16 who finished the course. In a community like Wilcannia this is no small achievement. Let us not forget that for a person who doesn't read and write even taking that first step to come into the room is a giant step. So I say to you all... be proud of what you have done for yourself and for your kids and for your community. I know you have discovered learning and it is so exciting. It fills me with immense pride when I see 
you all now doing your post literacy classes, using the computers, cooking healthy food and soon some of you'll be doing the Certificate II course in Catering (Jack Beetson, $31 / 8 / 12)$.

The graduations provided further evidence of the extent to which the community had taken ownership of the campaign and were providing much of the energy driving it. The hall was decorated by a team of volunteers and the cooking was done by two local community members, with assistance from the school staff and a local businessman. The young Baakintji dancers performed, accompanied on the didgeridoo by Owen Whyman, one of the facilitators. Community elders attended and spoke, and representatives of the facilitators and students also made speeches. Each graduate received a special certificate, which included the design from the Youth Centre literacy campaign banner. The final graduation, which was also a farewell for Chala, ended in the evening with a community dance, attended by several hundred people. According to one of the Yes I Can participants, 'It was the best day of my life.'

\section{Phase Three: Post-literacy}

The aim of Phase Three in a mass literacy campaign is to consolidate the learning that has occurred in the introductory classes by encouraging people to become part of the 'culture of literacy', and to engage in ongoing activities in which literacy and the learning which utilises and builds it are central. For some people, this may ultimately become a path back into more formal, accredited learning, while for others, it may remain at the level of informal and incidental activities, such as more literate practices at work, in the home and in community. As with the other phases, the underlying theory is based on the idea of literacy as a 'social practice', done with other people in social situations, not an autonomous skill, even though skill is part of it.

The key task was to develop a coordinated strategy to strengthen the graduates' newly acquired basic literacy over a minimum three month timeframe. The model aims to involve as many community organisations as possible in providing this post-literacy support, thus emphasising that the responsibility for overcoming illiteracy and supporting people who are trying to improve lies with the whole community. It is also about embedding into ongoing community life the development of the capacity of the low literate to become active agents in the development of themselves, their families and their community, through a gradual process of social inclusion. Post literacy activities following the first intake included non-formal computer classes at the Land Council offices, and a cooking class at the Women's Safe House. The timetable was deliberately kept to a minimum so 
it could be managed locally and required few resources, whilst maintaining the same daily routine (2 hours 3 to 4 times per week) from the Yes I Can classes. As with all the campaign activities, there were major challenges. As the Project Leader wrote in his Final Report:

The positive outcomes are even more remarkable because they were achieved against a local back drop of community crises and dislocation (Beetson, 2012)

Despite this, there was a 70 percent take-up of post literacy activities after the first graduation, with seven of the ten graduates involved in either classes, or work experience or both, while two of the three who did not join had left town for personal/family reasons. Two students were engaged to work as assistant instructors on post literacy activities and one of them was, at the end of this phase, engaged by LALC as a trainee Facilitator for intake 2 Yes I Can students. Four local agencies (LALC, Safe House, Shire Council and Save the Children) directly supported the phase three activities; and three others contributed resources. Following the second intake graduation, a similar program was developed, of computing, cooking classes, and supplementary literacy tutoring, this time provided by the local TAFE (Technical and Further Education), with whom the LALC had negotiated a partnership. In addition to these learning activities, work experience placements continued, at CDEP and the Safe House. Attendance and participation grew, because the first intake graduate employed by the LALC worked on the program, and some first intake graduates returned to join in the post-literacy activities.

In the last week, Western TAFE opened a new course, a Certificate II in Catering, based on the new partnership that had been developed by the LALC, who continued to pay an assistant teacher (a Yes I Can graduate) to work with the TAFE staff. This course was a direct response to needs expressed by graduates of Yes I Can, who want to start a small catering business in town as an income generating project. It is particularly noteworthy that six people have now enrolled in an entry level vocational qualification, and two people have obtained employment, one with the Shire and another with the Land Council. For this cohort, which had previously had very little interest or opportunity to work or do further study, this was a major breakthrough.

\section{Overall Findings}

The aim of the pilot was to discover first, whether the mass adult literacy campaign model, utilising the Yes I Can method, could be successfully applied in an Aboriginal community; and second, what would 
be involved in up-scaling it from community to regional level, and then to other regions. As the account given above has shown, it can be applied in an Aboriginal community and was, in fact, welcomed by that community. In terms of success, the enthusiastic participation of so many individuals and agencies, and the outcomes achieved by the graduates and others, are an indication that, for those who joined the campaign, it was indeed a success. However, it is important not to overstate what the evidence from this pilot demonstrates. The aim of a literacy campaign is to raise significantly the level of literacy in a region or a nation within a specific period of time. From this perspective, the important data are population level data, rather than individual outcome data. While this was a pilot, confined to one community, and not a full-developed campaign, it is still important to ask to what extent was there was significant change in the literacy rate at a population level, i.e. in the Wilcannia Aboriginal adult community. Table 2, below, summarises the evidence.

Table 2. Overall summary of community outcome

\begin{tabular}{|l|r|r|r|}
\hline & \multicolumn{1}{|c|}{ Male } & \multicolumn{1}{c|}{$\begin{array}{c}\text { Femal } \\
\text { e }\end{array}$} & \multicolumn{1}{l|}{ Total } \\
\hline 2011 Gensus & 120 & 159 & 279 \\
\hline Est. target @40\% & 48 & 64 & 112 \\
\hline Surveyed & 56 & 87 & 143 \\
\hline Identified need & 40 & 58 & 98 \\
\hline Starters & 14 & 29 & 43 \\
\hline Completions & 5 & 11 & 16 \\
\hline
\end{tabular}

The estimated target was based on the conservative assumption, that 40 percent (i.e. 112 people) of the adult population (at the 2011 census) had minimal literacy levels. In fact, 98 people self-identified or were identified by a family member through the initial survey and registration process, as interested in joining the campaign i.e. approximately 87 percent of our estimated potential target group. Of the 98 who were identified, 43 actually started class, that is, attended one or more sessions. If the initial estimates are correct, then we succeeded in reaching 38 percent of the target population with our two intakes, and 13 percent of this target population actually participated until the classes finished. In the end, if our initial assumptions were correct, this number of completions has reduced the percentage of low-literate people in the community by around 6 percent (from 40 to 34 percent). This is a deliberately conservative estimate, as some 
of the people who did not complete the 12 weeks of classes were seen to have improved in the time they were in class. It may also be the case that the initial estimate of those with low literacy was too high and/or that the total adult population over 15 was less than the number found in the 2011 census. On those assumptions, the reduction in the overall illiteracy/very low literacy rate might rise to 7 or 8 percent.

This outcome falls well short of reductions achieved in full-scale campaigns documented in other countries, such as in Nicaragua in 1980, where the reduction was in the order of 15-25 percent (Cardenal and Miller 1981). Therefore, we cannot say on the basis of this pilot that the mass literacy campaign model can be applied in an Aboriginal community to the same effect it has had in some other countries. However, on the basis of the lessons learned from the Wilcannia experience, it is reasonable to believe that a more dramatic improvement could be achieved by up-scaling the pilot to a regional level.

The pilot clearly demonstrated the capacity of the model to mobilise a community around the literacy issue. The Central School Principal, Michelle Nicholson, captured this in her interview:

There has been a lot of things happen in Wilcannia that have been done to the community. This project for me, the differences and the reasons why this has been embraced, is the fact that it is actually for the community, by the community. And, it's actually the community that is running the program. There's support there, like a lot of support obviously, but the leadership roles are being held by community members... It's the care with that that has made it successful. (Michelle Nicholson, Interview, 27/7/12).

The active participation of local staff in the campaign provides further evidence of the model's value in building community capacity. The four local facilitators, two women and two men, received substantial training in the model, beginning with the intensive training before the start of the first intake and continuing on the job for the next seven months. At the end of the first intake, one of the students asked to be trained as a facilitator also, and she received training from then until the end of the second intake and has continued to work in the post-literacy phase. The extent to which they embraced the idea of the model and understood its importance, as much to themselves as to the participants, was expressed by Owen Whyman in an interview:

...when they approached me about this, about being a facilitator, I jumped at the chance, because like I said, I've always wanted to do something to help my people ... It's a good feeling in your heart, because you know you're 
doing something for your people. And you feel proud on the inside, and there's no better feeling than that. (Owen Whyman, Interview, 26/7/12).

In addition to the Facilitators, many other local people developed an understanding of the campaign model, including the post-literacy coordinator, members of the local Working Group and the Community Working Party, staff in organisations which joined the Network of Supporters, and, not least, the participants themselves.

A collective 'systemization' (Carrillo 2010) of the evaluation data undertaken by the NAALCSC and the project team at a workshop in Alice Springs in late August identified several factors which had contributed to the model's success. First, the leadership of the campaign was taken by an Aboriginal community-controlled organisation which had legitimacy, authority, and resources, and was already identified as the leading development agency by community members and other important actors, including government. Second, the campaign employed local people in key roles, people who the community respected and trusted, and the campaign office became an open space where Aboriginal people were talking about and acting on the issue, making literacy 'everyone's business'. It was also seen as important that the local staff and Working Group members came from several family groups, creating links across community divisions and conflicts, with key community leaders and elders over time lending support to the campaign, by participating in its public activities. A further factor was the expertise and experience of the on-site Project Leader and his team, including the Cuban adviser who won the respect and friendship of the facilitators and participants, and of other people in the town, by virtue of his commitment to their struggle and to the principles of solidarity and respect which underpins the Cuban model. The Grenadian DVD lessons, and Chala's Cuban nationality and culture, proved a point of interest and attraction, as people discovered that they were part of a wider adult literacy movement among 'people of colour' in countries of the Global South, about which they wanted to know more. Resources were also crucial, in that there were sufficient funds to hold social events like the launch, the graduations and the regular BBQs, which made the campaign a 'whole-of-community' activity in which everyone could get involved, including the families of the participants and staff. Finally, and perhaps most importantly, the campaign generated a spirit of respect, compassion and solidarity for everyone involved, so that people felt safe and supported, not judged or 'put down', and began to believe in the possibility of a better future.

The evaluation workshop concluded that evidence from the pilot was sufficiently compelling to warrant the continued development of the model 
for use in Aboriginal communities, since literacy levels had been raised by a significant amount, with significant impacts on the lives of the individuals involved, their families and the whole community. Moreover, this had been achieved in a community where many previous efforts had failed. On this basis, the NAALSC decided to undertake two more pilots in the same region in western NSW in 2013, both to refine the model further, but also to test whether upscaling it produces a more substantial improvement in overall literacy levels.

\section{Conclusion}

The success of the pilot owes most to the extraordinary courage and perseverance of the participants, the facilitators and their families. It is appropriate, then, to end this paper with two local voices. First, one of the students who captured much of what this article has tried to convey in a powerful testimony on the impact of the campaign:

It's good, because when I was, like, 'using' (indicated injecting into forearm), I sort of lost it, you know, I forgot how to read and spell things you know. Then I came and done this here. And now I build a little bit up, and refreshing my memory - and I feel good about myself. Instead of doing rehab and doing it that way, my family bought me to my other family, and they looked after me and got me onto this. I just feel good about it.

I'd do the training to be the facilitator, just to keep it here. To encourage more to come along. 'Cos I know there's people out there that really need it. And it can make a difference ... even in the community too. It can build self-esteem up.

And, finally, on the question as to whether the campaign should continue, one of the local facilitators put it like this:

And this is the best thing that ever could have happened for this little town

... You know, don't stop at one town. Let's keep going. Let's keep it rolling on.... you've got to spread it along, spread the word, take it to other communities, and keep it alive. Keep it alive. 


\section{References}

Abadzi, H (1994) What we know about the acquisition of adult literacy: Is there hope? World Bank Discussion Papers, No. 245, World Bank, Washington DC.

Abendroth, M (2009) Rebel Literacy: Cuba's National Literacy Campaign and Critical Global Citizenship, Litwin Books, Duluth, MN.

Ah Chee, D, Beetson, J, and Boughton, B (1997) Indigenous Peoples' Education Rights in Australia, Paper presented at the Indigenous Rights, Political Theory and the Reshaping of Institutions Conference, August 8 - 10, Australian National University.

Allman, P (2010) Critical Education Against Global Capitalism: Karl Marx and revolutionary critical education, Sense Publishers, Rotterdam.

Archer, D (2005) Writing the Wrongs. International benchmarks on adult literacy, Global Campaign for Education, Johannesburg.

Arnove, R F, and Graff, H J, eds (2008) National Literacy Campaigns and Movements. Historical and comparative perspectives, Transaction Publishers, New Brunswick and London.

Australian Bureau of Statistics (2011) Census of Population and Housing. Wilcannia (SSC12499) Tables. Retrieved 24 July 2012 from www.abs.gov.au.

Beckett, J (2005) A Study of Aborigines in the Pastoral West of New South Wales, Oceania Monograph 55, University of Sydney, Sydney.

Beetson, J (1997) Adult Education and Indigenous Peoples, Paper presented at the Indigenous Panel, CONFINTEA V, retrieved 1 June 2013 from

http://www.teachingheritage.nsw.edu.au/section07/wdl_beetson.ph $\mathrm{p}$

Beetson, J (2012) On Site Project Manager's Final Report. Wilcannia Aboriginal Adult Literacy Campaign Pilot. (Unpublished), University of New England, Armidale.

Bell, S, Boughton, B, and Bartlett, B (2007) Education as a Determinant of Indigenous Health, in Anderson, I, Baum, F and Bentley, M, eds, Beyond Bandaids: Exploring the social determinants of Aboriginal health, Cooperative Research Centre for Aboriginal Health, Darwin, NT, pp 37-55.

Bhola, H S (1984) Campaigns for Literacy: Eight national experiences of the twentieth century, with a memorandum to decision-makers, UNESCO, Paris.

Bhola, H. S. (1999) Literacy Campaigns: A policy perspective, in Wagner, DA, Venezky, RL and Street, B, eds, Literacy: An international handbook, Westview Press, Boulder, CO.

Boughton, B (2000) What is the Connection between Aboriginal Education and Aboriginal Health? CRC ATH Occasional Paper Series, No. 2, 
Cooperative Research Centre for Aboriginal and Tropical Health, Darwin, NT.

Boughton, B (2009) Popular Education for Literacy and Health

Development in Indigenous Australia, Australian Fournal of Indigenous Education, vol 38, pp 103 - 108.

Boughton, B (2010) Back to the Future? Timor-Leste, Cuba and the return of the mass literacy campaign, Literacy and Numeracy Studies, vol 18, no 2, pp 23-40.

Boughton, B (2012) Adult Literacy, Popular Education and Cuban Educational Aid in Timor-Leste, in Hickling-Hudson, A, Gonzalez, JC and Preston, R, eds, The Capacity to Share: A study of Cuba's international cooperation in educational development, Palgrave Macmillan, New York, pp 197-216.

Caldwell, JC (1986) Routes to Low Mortality in Poor Countries, Population and Development Review, vol 12, pp 171-220.

Cardenal, F and Miller, V (1981) Nicaragua 1980: The battle of the ABCs, Harvard Educational Review, vol 51, no 1, pp 1-26.

Carrillo, AT (2010) Generating Knowledge in Popular Education: From participatory research to the systematization of experiences, International Fournal of Action Research, vol 6, nos 2-3, pp 196-222.

Durnan, D and Boughton, B (1999) Succeeding Against the Odds: The outcomes obtained by Indigenous students in Aboriginal community-controlled colleges, National Centre for Vocational Education Research, Adelaide.

Durnan, D (2012) Senior Technical Consultants Final Report. Wilcannia Aboriginal Adult Literacy Campaign Pilot. (Unpublished), University of New England, Armidale.

Federation of Independent Aboriginal Education Providers (FIAEP) (1997) Best Practice and Benchmarking in Aboriginal Community-Controlled Adult Education, Australian National Training Authority (ANTA), Brisbane, Qld.

Freire, $\mathrm{P}$ (1972) Pedagogy of the Oppressed (MB Ramos, trans), Penguin Education, Harmondsworth.

Freire, P (1978) Pedagogy in Process: The letters to Guinea-Bissau (CSJ Hunter, trans), Writers and Readers Publishing Cooperative, London.

Freire, P and Macedo, D (1987) Literacy: Reading the word and the world, Bergin \& Garvey, South Hadley, MA.

Gibson, L (2006) Articulating Culture(s): Being black in Wilcannia, unpublished $\mathrm{PhD}$ thesis, Macquarie University, Sydney.

González, N (2005) The Outlook for Popular Education at the Time of the 6th General Assembly of CEAAL. Adult Education and Development, no 64.

Goodall, H (2001) 'Speaking what our mothers want us to say': Aboriginal women, land and the Western Women's Council in New South 
Wales, 1984-85, in Brock, P (ed), Words and Silences: Aboriginal women, politics and land, Allen \& Unwin, Crows Nest, NSW, pp 18-55.

Gray, A and Smith, L (1995) Is There a Low Road to Aboriginal Health, Paper presented at the Aboriginal Health: Social and cultural transitions conference, Darwin, NT.

Jones, PW (1990) UNESCO and the Politics of Global Literacy, Comparative Education Review, vol 34, no 1 (Special Issue on Adult Literacy), pp 4160.

Kapoor, D and Jordan, S (2009) Education, Participatory Action Research, and Social Change: International perspectives, Palgrave Macmillan, New York.

Kemmis. S and McTaggart, R, eds (1988) The Action Research Planner (second edition), Deakin University Press, Geelong, Victoria.

Latin American Group of Specialists in Literacy and Written Culture [GLEACE] (2009) On Illiteracy and Literacy. Declaration of the members of the Latin American Group of Specialists in Literacy and Written Culture (GLEACE), EAEA Newes 2009, retrieved 12 June 2010 from www.intercultural-learning.net//

Lind, A (2008) Literacy for All: Making a difference, UNESCO, Paris.

Luke, A and Freebody, P (1999) Further Notes on the Four Resources Model. Retrieved 7 May 2009 from http://www.readingonline.org/research/lukefreebody.html

McLean, P (2012) Wilcannia Aboriginal Adult Literacy Campaign Pilot (WAALC) Literacy and Numeracy Assessments, unpublished ACSF Consultant's Report, Melbourne.

Miller, VL (1985) Between Struggle and Hope: the Nicaraguan literacy crusade, Westview Press, Boulder, CO.

Robinson-Pant, A (2000) Why Eat Green Cucumbers at the Time of Dying? Women's literacy and development in Nepal, UIE, Hamburg.

Rogers, A (2011) Why Literacy Matters: Understanding the effects of literacy education for adults, International Review of Education, vol 57, nos 5-6, pp 757-760.

Saldanha, D (2010) Decentralizing Partnerships for Literacy and Adult Education: The Indian experience, Indian Fournal of Adult Education, vol 71, no 4, pp 52-68.

Sandiford, P, Cassel, J, Montenegro, M, and Sanchez, G (1995) The Impact of Women's Literacy on Child Health and its Interaction with Access to Health Services, Population Studies, vol 49, pp 5-17.

Street, B (2001) Literacy and Development: Ethnographic perspectives, Routledge, London.

Street, BV (2011) Literacy Inequalities in Theory and Practice: The power to name and define, International Fournal of Educational Development, $\mathrm{Vol}$ 31, no 6, pp 580-586.

UNESCO (2005) EFA Global Monitoring Report 2006: Education for all - literacy for life, UNESCO, Paris. 
UNESCO (2006) Study on the Effectiveness and Feasibility of the Literacy Training

Method Yo Si Puedo, retrieved 7 May 2010 from

http://unesdoc.unesco.org/images/0014/001468/146881e.pdf

Wagner, DA (2001) Literacy and Adult Education, UNESCO, Paris.

Wagner, DA (2011) What Happened to Literacy? Historical and conceptual perspectives on literacy in UNESCO, International Fournal of Educational Development, vol 31, no 3, pp 319-323.

${ }^{i}$ An earlier version of this paper was presented at an international Conference in Havana in February 2013, entitled Pedagogia 2013. We acknowledge the useful suggestions for revision from our two anonymous reviewers and the journal editors.

ii Save the Children is an Australian non-government children services provider 